\title{
Sociocultural integration and second language proficiency following migration
}

\begin{abstract}
This presentation reports on an investigation into the links between proficiency level in the second language and degree of sociocultural integration in the host country following migration. Participants were 149 highly-educated young-adult sequential Polish-English bilinguals who had been resident in the UK for an average of eight years. Statistical analyses backed up with interview data show that the degree of acculturation and sociocultural integration are strongly linked to the ultimate proficiency level in the new language following migration.
\end{abstract}

Résumé : L'article examine la corrélation possible entre le niveau de compétence dans la langue seconde (L2) et le niveau d'intégration socioculturelle des migrants dans le pays d'accueil. Une étude a été réalisée auprès de 149 jeunes adultes très qualifiés, tous bilingues polonais-anglais, qui résidaient au Royaume-Uni depuis huit ans en moyenne. Les analyses statistiques et les données recueillies en entretien montrent que le niveau d'acculturation et d'intégration socioculturelle est étroitement lié au niveau de compétence acquis dans la langue seconde après la migration.

\section{Background}

Migration is one of the most widely debated topics in the modern world. Movement of people across national borders is a subject of negotiation in international relations; it also sparks discussions about cultural and linguistic integration, as well as social cohesion within individual nation states. There is a strong link between migration, integration and language (Esser 2006). The ability to use the official language of the new country of residence is a crucial component of successful integration into the new society. Language enables communication between members of the society; it is also a carrier of sociocultural values and norms. Language is a medium in the processes of sociocultural integration. The level to which the new language (L2) is attained by a new language user is linked to the user's ability to participate in the social, cultural and organiza-

Kate Hammer, Birkbeck, University of London, United Kingdom, E-mail: k.hammer@bbk.ac.uk 
tional life of the new society (Esser 2006). Higher levels of L2 proficiency enable a more engaged character of settlement, for the language user is able to understand the surrounding sociocultural reality to a deeper level directly from authentic sources, as opposed to translation. Linguistic attainment is thus an important factor in sociocultural integration, as it helps the new language user to become an independent member of the new society.

Second language acquisition (SLA) is a complex process which engages various mental faculties, and which has been linked to different SLA-oriented variables including motivation, age of onset and context of L2 acquisition (Cook and Singleton 2014). Immersion in the target language for a prolonged period of time has also been linked to successful language attainment due to increased exposure to the new language in a variety of contexts (Singleton, Regan, and Debaene 2013). In addition, levels of attainment in L2 have been linked to the acquisition of the target culture. Acculturation is defined as a "process of cultural and psychological change" (Berry 2005: 698). The Acculturation Model for SLA (Schumann 1986) combines sociocultural and psychological factors in respect to the acquisition of a new language following migration. The model predicts that the L2 learner will acquire the target language to the level to which they acculturate to the new culture. According to Schumann (1986), successful acquisition of the L2 in the circumstances of migration is tightly linked to the extent to which the L2 learner assimilates to the new culture. Acculturation has been described as one of the most causal variables in SLA, and it has been employed in poststructuralist approaches to L2 learning and use (Pavlenko 2002).

This summary presents the results of the study, which investigated self-reported proficiency level in L2 following migration in native Polish L1 speakers who migrated to the UK in early adulthood. The independent variables included sociolinguistic and language acquisition factors, namely: acculturation level; frequency of L2 use; social network profile; age at migration; length of residence; age of onset of second language acquisition (AoA); current age; context of L2 acquisition; education level; gender; and motivation behind migration (Hammer 2012; Hammer and Dewaele 2015).

\section{Research question}

To what extent is self-reported proficiency in L2 following migration linked to:

(a) Acculturation level

(b) Frequency of L2 use following migration

(c) Social network profile

(d) Age of onset of L2 acquisition 
(e) Age at migration

(f) Context of L2 acquisition

(g) Current age

(h) Length of residence

(i) Education level

(j) Gender

(k) Motivation behind migration

\section{Methodology}

Participants were 149 native speakers of Polish who migrated to the UK in early adulthood. The average age at migration was 23 (range $18-41$, mean $=23.6, \mathrm{SD}=$ 3.8 ), and the average current age was 31 (range 23-45, mean = 31.1, $\mathrm{SD}=4.7$ ). The majority of the participants (128) had migrated by the age of 26 . All participants were university or college graduates, of whom $86 \%$ were female and $14 \%$ male. $45.6 \%$ of the respondents rated themselves as proficient users of English L2; 38.3\% admitted native-like proficiency; 14.1\% declared an advanced level of L2 use and 2\% self-rated as intermediate level L2 users.

Participants completed an online questionnaire which consisted of both closed and open-ended questions (Hammer 2012). In addition, 14 participants were interviewed by the researcher. The design included both quantitative and qualitative approaches. A one-sample Kolmogorov-Smirnov test revealed that the values for self-reported proficiency level in L2 were not normally distributed $(\mathrm{Z}=2.9, \mathrm{p}<$.0001); therefore Spearman's rank correlation, Kruskal-Wallis and Mann-Whitney tests were used in statistical analyses.

\section{Results}

Quantitative data analyses revealed:

(a) A significant effect of acculturation level on self-reported proficiency level in L2 (Kruskal-Wallis test; $\left.\chi^{2}=11.1 ; \mathrm{p}<.004\right)$; completely and highly acculturated participants had significantly higher levels of self-reported proficiency than moderately and slightly acculturated participants.

(b) A significant effect of frequency of L2 use on self-reported proficiency level in L2 (Kruskal-Wallis test; $\chi^{2}=10 ; p<.018$ ); participants who used the L2 more frequently attained higher levels of L2-proficiency than those who used predominantly L1. 
(c) A significant effect of social network profile on self-reported proficiency level in L2 (Kruskal-Wallis test; $\chi^{2}=7.9 ; p<.019$ ); higher levels of self-reported proficiency were recorded for participants whose social networks included both L1- and L2-speaking interlocutors, or majority L2-speaking interlocutors, as opposed to those whose social networks were predominantly L1speaking.

(d) A significant effect of AoA on self-reported proficiency level in L2 (KruskalWallis test; $\chi^{2}=6.3 ; \mathrm{p}<.042$ ); participants who started learning the L2 at a lower age attained a higher level of L2-proficiency.

(e) No significant effect of age at migration on self-reported proficiency level in L2 (Kruskal-Wallis test; $\chi^{2}=2.4, p=.303$ ).

(f) No significant effect of context of L2 acquisition on self-reported proficiency level in L2 (Kruskal-Wallis test; $\chi^{2}=4.3 ; \mathrm{p}=.116$ ).

(g) A significant link between current age and self-reported level of proficiency (Spearman's Rank Correlation; Rho $=.176 ; \mathrm{p}<.032$ ); older participants felt more proficient in $\mathrm{L} 2$ than younger participants.

(h) A significant effect of length of residence on the self-reported proficiency level in L2 (Kruskal-Wallis test; $\chi^{2}=7.1 ; p<.029$ ); there was a monotonic increase in L2 proficiency levels between participants whose length of residence was under five years, those whose residency ranged from five to ten years, and those whose residency reached or exceeded ten years.

(i) No significant effect of education level on self-reported proficiency level in L2 (Kruskal-Wallis test; $\chi^{2}=2.25 ; \mathrm{p}=.324$ ).

(j) No significant effect of gender on self-reported proficiency level in L2 (MannWhitney test; $\mathrm{U}=1342 ; \mathrm{p}=.991$ ).

(k) No significant effect of motivation behind migration on self-reported proficiency level in L2 (Kruskal-Wallis test; $\chi^{2}=.492 ; \mathrm{p}=.782$ ).

Qualitative data analyses and the feedback from the interviews and open questions confirmed the statistical findings.

\section{Discussion}

The findings revealed that the effect of acculturation level on self-reported proficiency in L2 had the strongest statistical effect when compared to all other variables (Hammer and Dewaele 2015). Participants with higher acculturation levels were found to have higher levels of proficiency in English L2. Other variables which were found to have an effect on the level of attainment in L2 following migration were, in decreasing order of statistical significance: frequency of L2 use; 
social network profile; length of residence; current age and AoA. Participants who used English L2 more frequently and whose social networks included more English-speaking interlocutors were found to have higher levels of L2 proficiency when compared to participants whose frequency of L2 use was low, and whose social networks were predominantly L1-oriented. Two temporal variables were also found to be linked to proficiency level in L2 namely, length of residence and current age. Participants with greater length of residence in the host country, as well as older participants, were found to have higher self-reported proficiency levels as opposed to younger participants, and those whose length of residence was shorter than five years. Participants whose length of residence reached or exceeded ten years were found to have the highest levels of L2 proficiency (Hammer and Dewaele 2015). Also AoA was found to be linked to proficiency levels; participants who started learning the L2 earlier in life recorded overall higher levels of proficiency in L2, which links with previous studies investigating the effects of AoA on L2 attainment (cf. Cook and Singleton 2014). No links were established between self-reported proficiency and education level, gender, age at migration, context of L2 acquisition and motivation behind migration.

The findings showed that L2 proficiency following migration is tightly linked to acculturation level, which links with the Acculturation Model for SLA (Schumann 1986). Acculturation is understood as a crucial component in L2 attainment in the circumstances of migration, which supports the notion that migration, integration and language are significantly interconnected (Esser 2006). The findings provide empirical evidence that linguistic acquisition develops alongside and in relation to cultural acquisition (cf. Singleton, Regan, and Debaene 2013). The present study provides support for the notion that acculturation is a powerful causal variable in processes of SLA (Pavlenko 2002).

\section{Conclusion}

Acculturation proved to be tightly linked to L2 attainment following migration; the statistical significance of the effect of acculturation level on self-reported proficiency in L2 was higher than any other variable tested as part of the study. The findings suggest that linguistic integration of adult migrants in the host country is tightly linked to acculturation levels, and that linguistic attainment does not happen independent of sociocultural integration. 


\section{References}

Berry, John W. 2005. Acculturation: Living successfully in two cultures. International Journal of Intercultural Relations 29. 697-712.

Cook, Vivian J. \& David Singleton. 2014. Key topics in second language acquisition. Bristol: Multilingual Matters.

Esser, Hartmut. 2006. Migration, language and integration. AKI Research Review 4. Programme on Intercultural Conflicts and Societal Integration, Social Research Centre Berlin.

Hammer, Kate. 2012. Web questionnaire on language use and language choice in bilinguals (E-PLUS). Unpublished manuscript, University of London.

Hammer, Kate \& Jean-Marc Dewaele. 2015. Acculturation as the key to the ultimate attainment? The case of Polish-English bilinguals in the UK. In Fanny Forsberg Lundell \& Inge Bartning (eds.), Cultural migrants and optimal language acquisition, 179-202. Bristol: Multilingual Matters.

Pavlenko, Aneta. 2002. Poststructuralist approaches to the study of social factors in L2. In Vivian Cook (ed.), Portraits of the L2 user, 277-302. Clevedon: Multilingual Matters.

Schumann, John H. 1986. Research on the Acculturation Model for second language acquisition. Journal of Multilingual and Multicultural Development 7(5). 379-392.

Singleton, David, Vera Regan \& Ewelina Debaene (eds.). 2013. Linguistic and cultural acquisition in a migrant community. Bristol: Multilingual Matters. 